1 Co-benefits of energy-efficient air conditioners in the residential building

\title{
2 sector of China
}

3 Xu Wang ${ }^{\S, t, \neq, *}$, Pallav Purohit ${ }^{\ddagger, *}$, Lena Höglund-Isaksson ${ }^{\ddagger}$, Shaohui Zhang ${ }^{\dagger, \neq}$, Hong Fang ${ }^{\dagger}$

$4 \quad{ }^{\S}$ College of Economics and Management, Beijing University of Technology, China

$5 \quad{ }^{\dagger}$ School of Economics and Management, Beihang University, China

$6 \quad{ }^{\ddagger}$ International Institute for Applied Systems Analysis (IIASA), Laxenburg, Austria

$7 \quad$ *Corresponding authors: wngxu@buaa.edu.cn, purohit@iiasa.ac.at 


\section{Abstract}

9 Electricity demand for room air-conditioners (ACs) is growing significantly in China in response to rapid economic development and mounting impacts of climate change. In this

11 study, we use the bottom-up model approach to predict the penetration rate of room ACs in

12 the residential building sector of China at the provincial level, with the consideration of the

13 urban-rural heterogeneity. In addition, we assess co-benefits associated with enhanced energy

14 efficiency improvement of AC systems and the adoption of low global warming potential

15 (GWP) refrigerants in AC systems. The results indicate that the stock of room ACs in China

16 grows from 568 million units in 2015 to 997 million units in 2030 and 1.1 billion units in

17 2050. The annual electricity saving from switching to more efficient ACs using low-GWP

18 refrigerants is estimated at almost 1000 TWh in 2050 when taking account of the full

19 technical energy efficiency potential. This is equivalent to approximately $4 \%$ of the expected

20 total energy consumption in the Chinese building sector in 2050 or the avoidance of 284 new

21 coal-fired power plants of $500 \mathrm{MW}$ each. The cumulative $\mathrm{CO}_{2} \mathrm{eq}$ mitigation associated with

22 both the electricity savings and the substitution of high-GWP refrigerants makes up 2.6\% of

23 total business-as-usual $\mathrm{CO}_{2}$ eq emissions in China over the period 2020 to 2050. The

24 transition towards the uptake of low-GWP refrigerants is as vital as the energy efficiency

25 improvement of new room ACs, which can help and accelerate the ultimate goal of building a

26 low-carbon society in China. 
27 Table of Contents (TOC)/Abstract Art

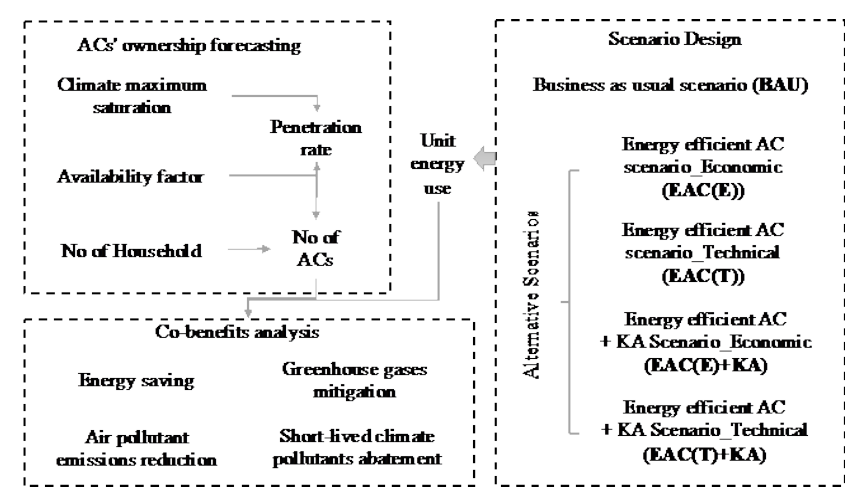




\section{INTRODUCTION}

32 The global energy consumption of space cooling in the building industry is growing faster than in many other industries ${ }^{1}$ (i.e. transportation industry and manufacturing industry) and has more than tripled between 1990 and $2016^{2}$. The increase is expected to continue in the next few decades ${ }^{3-6}$. Space cooling is expected to account for an ever-increasing share of energy use with particularly strong growth in emerging economies. Until 2050, the three countries China, India, and Indonesia alone will account for half of the global growth in cooling energy demand ${ }^{2,7}$. Over the last two decades, China noted the fastest growth worldwide in energy demand for space cooling in buildings, increasing at 13\% per year since 2000 and reaching nearly 400 terawatt-hours (TWh) of electricity consumption in $2017^{8}$. The increase in energy consumption since 2000 is driven by increasing income and growing demand for thermal comfort. As a result, space cooling accounted for more than $10 \%$ of total electricity consumption in China since 2010 and around 16\% of the peak electricity load in $2017^{8}$. Cooling-related carbon dioxide $\left(\mathrm{CO}_{2}\right)$ emissions from electricity consumption consequently increased fivefold between 2000 and $2017^{8}$, given the strong reliance on coalfired power generation in China. Already, China is the country worldwide with the largest production and use of air conditioners (ACs), as the country manufactured around $70 \%$ of total world output and consumed approximately $40 \%$ of global AC sales in $2017^{8-10}$. The penetration rates of room ACs in China have increased from around 20\% in 1997 to about 130\% in 2018 for urban residential buildings and from below 1\% in 1997 to around 50\% in 2018 for rural residential buildings ${ }^{11}$ (see: Figure S1 of the SI). To alleviate the pressures of energy consumption and associated greenhouse gas (GHG) and air pollutant emissions brought about by the increase in space cooling demand, China has released a series of

54 household energy efficiency standards since $1989^{12-16}$ (see: Table S1). However, the energy 55 efficiency of the units sold in the market differs enormously ${ }^{2,8}$ (see: Figure S2). Currently, 

the average energy efficiency of room ACs sold is $60 \%$ less than the efficiency level of the best available technology and 20\% lower than the average technology level available in China ${ }^{8}$. At the provincial level, penetration rates of room ACs for urban and rural areas are presented in Figure S3 of the SI.

A review of the literature indicates that there is a large potential for the usage of more energy-efficient ACs in the building sector. The application of energy-efficient ACs has significant potential for electricity savings and associated reductions in GHG and air pollutant emissions ${ }^{2,8,17-21}$. According to the recent Scientific Assessment of Ozone Depletion $^{22}$, an energy efficiency improvement of $30 \%$ in mini-split ACs is estimated to be technically and economically feasible as well as cost-effective in many economies ${ }^{22}$. At the global level, the International Energy Agency (IEA) estimated that under a baseline scenario the energy requirements of space cooling would triple by 2050, reaching 6200 TWh per year, whereas in an efficient cooling scenario only 3400 TWh per year would be required, which is $45 \%$ lower than that in the baseline ${ }^{2}$. This saving potential is equivalent to the total electricity consumption of the European Union in 2016. At the regional level, Grignon-Masse et al. (2011) assessed the environmental impacts of energy-efficient European ACs using a lifecycle analysis approach ${ }^{76}$. Borg and Kelly (2011) focused on the electricity consumption and peak load impacts of appliance efficiency improvements in European households ${ }^{77}$. At the national level, several studies evaluated the energy savings, emissions reductions, and economic benefits related to energy-efficiency standards and improvements for ACs and other appliances. Rosas-Flores et al. (2011) estimated the energy savings and $\mathrm{CO}_{2}$ emission reduction potentials of urban and rural household appliances, including ACs, in Mexico ${ }^{78}$. Cardoso et al. (2012) employed a bottom-up model to evaluate the impacts of energyefficient ACs in Brazil on electricity savings and GHG mitigation ${ }^{17}$. Based on the estimation 
concluded that an annual electricity saving of 322 GWh per year could be obtained from a

82

83

84 switch to energy-efficient ACs in Brazil. Phadke et al. (2014) estimated the electricity demand of room ACs in India by 2030 considering factors such as climate change and income growth using market data on the penetration of ACs in different income classes and climatic regions ${ }^{23}$. The total electricity saving potential from efficient room ACs using the best available technology would reach over 118 TWh in 2030 in India with potential peak demand saving found to be $60 \mathrm{GW}$. This is equivalent to avoiding 120 new coal-fired power plants of 500 MW each. McNeil et al. (2019) analyzed the impact of energy-efficient appliances on Indonesia’s peak load, finding that ACs will be the main driver of peak growth by $2025^{79}$. Similarly, IEA (2019) explored the major trends and challenges brought about by the rapid uptake of room ACs in China. The findings indicated that greater affordability, climate change, as well as changing occupant behavior would significantly increase cooling energy use ${ }^{8}$. IEA (2019) concluded that the annual energy demand would be 200 TWh lower in 2030 under the efficient cooling scenario relative to the baseline scenario. Another recent study by Karali et al. (2020) modeled the costs and benefits of recently proposed new room AC minimum energy performance standards (MEPS) in China and observed that the new standards would bring cumulative $\mathrm{CO}_{2}$ reductions of $12.8 \%$ between 2019 and $2050^{80}$.

Furthermore, the benefits of switching to new energy-efficient ACs are not only coming from the efficiency improvement caused by the AC system (e.g. more efficient compressors, heat exchangers, etc.), but also from the replacement of high global warming potential (GWP) refrigerants used as coolants in ACs ${ }^{24-26}$. Normally, the refrigerants e.g., chlorofluorocarbons (CFCs), hydrochlorofluorocarbons (HCFCs), and hydrofluorocarbons (HFCs), are thousands of times more powerful GHGs than $\mathrm{CO}_{2}$ on a mass-equivalent basis ${ }^{27}$, ${ }^{28}$ (see details in Section S3 of SI). While the use of CFCs has been successfully phased-out, HCFCs are currently in the process of being phased-out under the Montreal Protocol ${ }^{29}$. The 
ban on the use of CFCs in developing countries following the Montreal Protocol was fully implemented in $2010^{30}$, with China having implemented it ahead of schedule in $2006{ }^{31}$, however, full enforcement may yet to be completed ${ }^{86}$. The Kigali Amendment (KA) to the Montreal Protocol adopted in October 2016 and has entered into force in January 2019, is a

110 global agreement to phase-down the consumption of HFCs by $2050^{32}$. The KA aims to limit and eventually significantly reduce emissions of HFCs through a differentiated phase-down

112 of HFCs across countries over the next three decades. The associated conversion of

113 equipment from appliances using HFC refrigerants with high GWPs to low GWP refrigerants

114 provides an unprecedented opportunity to consider other possible technological

115 improvements that can offer additional climate co-benefits. The use of low GWP refrigerants

116 as a replacement for conventional HFCs offers an opportunity to redesign the equipment with

117 improved energy efficiency. In the literature, few attempts have been made to assess the

118 impact of enhanced energy efficiency improvement of AC systems and transitions to low-

119 GWP refrigerants. Höglund-Isaksson et al. (2017) analyzed the global abatement costs of

120 achieving the substantial reductions in HFC consumption agreed in the KA and incorporated

121 possible energy efficiency improvements when using alternative substances and technologies

122 to switch away from HFCs ${ }^{33}$, however, without considering the impact from simultaneously

123 improving the AC system (heat exchangers, compressors, valves, etc.). Similarly, Purohit et

124 al. (2018) analyzed the impacts of the KA to phase-down HFCs in Asian countries ${ }^{34}$. These

125 studies find that full compliance with the KA could save about 3000 TWh of electricity in

126 Asian countries over the period 2018 to 2050 due to a transition to appliances using low-

127 GWP refrigerants. This corresponds to an estimated $0.5 \%$ of expected cumulative electricity

128 consumption in Asia over the same period. In contrast, IEA (2018) assessed the energy

129 efficiency improvement due to enhanced AC systems ${ }^{2}$, however, without explicitly

130 considering efficiency improvements from the transition to low-GWP refrigerants as such. In 
a recent study, Purohit et al. (2020) account for both types of energy efficiency enhancements and find that if technical energy efficiency improvements are fully implemented together with the HFC phase-down under the KA, the resulting electricity savings could exceed a fifth

134 of expected future global electricity consumption ${ }^{47}$.

135 The distinction between top-down and bottom-up model approaches is interesting because 136 they can sometimes produce opposite outcomes for the same problem. Grubb et. al. (1993) state that the top-down approach is associated with -but not exclusively restricted to - the "pessimistic" economic paradigm, while the bottom-up approach is associated with the “optimistic” engineering paradigm ${ }^{84}$. The building stock energy models use both top-down

140 and bottom-up approaches ${ }^{85}$. The top-down methods start with the aggregated energy

141 consumption for a given region and time, then disaggregate into sectors according to e.g.,

142 building function or spatial proximity, and typically factor in the interrelationships between

143 the energy sector and other variables such as economic and technological factors. The

144 bottom-up methods work at an individual level calculating the energy consumption of

145 individual end-uses (e.g. cooking, heating/cooling, lighting) or buildings, then summing them

146 up to represent the required region. It may be noted that the bottom-up approach is commonly

147 used in co-benefits estimation as it e.g., allows for simulating a partial market equilibrium

148 with fixed relative prices ${ }^{82}$, identifying least-cost technology mixes for exogenous demand,

149 and/or simulating specific sectoral policies by setting exogenous environmental constraints ${ }^{83}$.

150 In this study, we have used a bottom-up engineering approach to model the stock of room

151 ACs and assess the co-benefits without considering the extended impacts e.g., on relative 152 prices and equilibrium in the energy market. Climate and air pollution co-benefits of space 153 cooling in the Chinese residential building sector are assessed by taking account of a)

154 regional and urban/rural heterogeneities (including macroeconomic factors, geographic,

155 demographic factors, household structure, etc. ) and climatic zone differences among 
provinces across China; and b) technical and economic energy efficiency improvements of

157 AC system (i.e., heat exchangers and compressors) and the transition towards low-GWP

158 refrigerants.

159

160

\section{MATERIALS AND METHODS}

161 In accordance with a bottom-up approach, co-benefits of the uptake of energy-efficient ACs

162 in the Chinese residential building sector by 2050 are assessed in a four-step procedure. First,

163 the ownership of room ACs by Chinese households is projected considering regional and

164 urban/rural heterogeneities (including macroeconomic/demographic factors, and household

165 structure, etc.) and changing climatic conditions (measured by cooling degree days, CDDs).

166 In a second step, the unit energy consumption (UEC) of room ACs is estimated as a function

167 of CDDs and household income levels to assess the energy consumption in the business-as-

168 usual (BAU) scenario. In a third step, two sets of alternative scenarios are developed: a)

169 considering only the technical and economic UEC potentials due to enhanced energy

170 efficiency of the room ACs, and b) taking into account both the transition towards low-GWP

171 refrigerants and the technical and economic UEC potentials. Finally, co-benefits in terms of

172 reduced GHG and air pollutant emissions are estimated using the electricity savings derived

173 from the alternative scenarios.

$174 \quad$ 2.1 Modeling Ownership of ACs

175 To estimate the number of room ACs in the Chinese residential building sector, we assume

176 that both energy consumption per unit and the proportion of households owning air-

177 conditioners (penetration rate) depend on the climatic condition and income level ${ }^{35}$, both

178 being higher in warmer and wealthier places (e.g. urban areas in warm regions). The

179 penetration of ACs in a province is formulated as a function of the climate maximum 
saturation (CMS) for that province and of the percentage of the CMS attained at that time in the region (availability) as shown in Eq. (1).

$$
P R_{i, t}=C M S_{i, t} \times A F_{i, t}
$$

where $P R_{i, t}$ represents the penetration rate of room ACs in the $i^{t h}$ province in $t^{t h}$ year, $C M S_{i, t}$ the climate maximum saturation in the $i^{\text {th }}$ province in $t^{t h}$ year, and $A F_{i, t}$ the availability of the $i^{t h}$ province in the $t^{\text {th }}$ year.

CMS is derived from the assumption that the maximum penetration rate is the maximum saturation for a climate with a given amount of $\operatorname{CDDs}^{35}$. The relationship between maximum saturation and CDD is exponential, as developed by Sailor and Pavlova (2003) ${ }^{36}$ for 39 cities in the United States and modified by McNeil and Letschert (2008) ${ }^{35}$ for developing countries (including China) as shown in Eq. (2).

$$
C M S_{i, t}=1-0.949 \times \exp \left(-0.00187 \times C D D_{i, t}\right)
$$

The availability of ACs as a function of household income (HHI) is assumed to develop along a logistic function ${ }^{35,38}$, with a threshold point beyond which ownership increases rapidly ${ }^{37-40}$, as shown in Eq. (3):

$$
A F_{i, t}=\frac{\alpha_{i, t}}{1+\gamma_{i, t} \exp \left(-\beta_{i, t} \times H H I_{i, t}\right)}
$$

where $\alpha_{i, t}$ is the maximum value of $A F_{i, t}$, together with $\beta_{i, t}$ and $\gamma_{i, t}$ being regression coefficients estimated for the $A F_{i, t}$ of each province.

Further details and data sources on CDDs, macro-economic parameters at the provincial level, and availability of room air-conditioners are provided in Section S2 of the SI.

\subsection{Unit Energy Consumption}

The energy consumption of ACs is not only related to the ownership and CDDs but also the income level of the household. Due to the high electricity consumption of ACs, wealthy 
203 households are likely to use it more frequently and for longer periods, while low-income

204 households, despite owning ACs, will use it occasionally when necessary ${ }^{8,35,39}$. Hence, 205 consistent with the method used in McNeil and Letschert (2008) ${ }^{35}$ and Kitous and Després 206 (2018) ${ }^{39}$, we set the model of unit energy consumption (UEC) of AC as a function of the 207 climatic conditions (i.e. CDDs) and the household income (HHI) level, as shown in Eq. (4).

$$
U E C=410 \cdot \ln (C D D)+0.033 \cdot \ln (C D D) \cdot H H I-2577
$$

To assess UEC we have used historical data obtained from Mendes et al. (2014) ${ }^{41}$ and Guo et al. (2017) ${ }^{42}$ for 11 provinces in different climatic zones of China (see Figure S4 of the SI).

\subsection{Scenarios Design}

212 Apart from the BAU scenario, we have developed four alternative scenarios (see Figure S5)

213 to assess the electricity savings and co-benefits associated with enhanced energy efficiency

214 improvements of AC systems and a transition towards low-GWP refrigerants. The first two

215 alternative scenarios only consider the technical and economic efficiency improvement due to the AC system optimization (e.g. using efficient compressors, heat exchangers, valves, etc.),

217 while the last two alternative scenarios consider both the technical/economic energy

218 efficiency improvement of ACs and the energy efficiency improvement from transitioning to 219 a low-GWP refrigerant (i.e. HC-290, GWP $100=1)^{22}$ from high-GWP HFCs (i.e. HFC-410A, $220 \mathrm{GWP}_{100}=1924$ or HFC-32, GWP $\left.100=677\right)^{45}$, as required to comply with the KA (see Section S3 of the SI). In the economic energy-efficient AC scenario “EAC(E)”, the UEC improvement is set to $30 \%$, and in the technical energy-efficient AC scenario "EAC(T)" the energy efficiency improvement is set to $60 \%{ }^{43,47}$. The energy efficiency improvement is

$22436 \%$ in the economic energy-efficient AC plus transition towards low-GWP refrigerants named as "EAC(E)+KA" scenario, whereas the energy efficiency improvement is assumed to

$22672 \%$ in the technical energy-efficient AC plus transitioning towards low-GWP refrigerants ${ }^{23}$, 44, ${ }^{47}$ named as "EAC(T)+KA" scenario (See details in Table 1). 
In consistency with assumptions in Purohit et al. (2020), the estimated electricity saving

229

230

231

232

233

234

235

236

237

238

239

240

241

242 potential in 2025 and 2030 is constrained by inertia in technology uptake resulting in a gradual phase-in of new technology and with maximum applicability only assumed possible from 2035 onwards ${ }^{47}$.

\subsection{Co-benefits analysis}

The methodology for estimating co-benefits in terms of electricity savings and the associated reduction in GHGs and air pollutants is described in Section S4 of the SI. In the BAU scenario, total energy consumption in room ACs is estimated using the number of households, the penetration rate of room ACs (Eq. (1)), and UEC (Eq. (4). The electricity savings in the alternative scenarios are estimated using different energy efficiency assumptions (technical and economic energy efficiency potential) due to systems improvement and transition towards low-GWP refrigerants under the KA. The technical and economic efficiency gains calculated are from improvements in the equipment (heat exchangers, compressors, valves etc.) and using low-GWP (e.g. HC-290) refrigerants. The Greenhouse gas - Air pollution Interactions and Synergies (GAINS) model developed by IIASA ${ }^{46}$ contains a database on emission factors for a range of air pollutants and GHGs from global energy consumption. From this database, we take the implied emission factors for $\mathrm{CO}_{2}, \mathrm{CH}_{4}$, air pollutants (sulfur dioxide, $\mathrm{SO}_{2}$; nitrogen oxides, $\mathrm{NO}_{\mathrm{x}}$; and fine particulate matter, $\mathrm{PM}_{2.5}$ ), and short-lived climate pollutants (SLCPs) (e.g. black carbon, BC; and organic carbon, OC) that reflect the expected region/province- and year- specific fuel mixes used in power plants in the IEA’s World Energy Outlook (WEO) 2018 Current Policies Scenario (CPS), New Policies Scenario (NPS) and Sustainable Development Scenario (SDS), respectively, in the timeframe to 2050 (see Figure S6 for details). The CPS scenario only considers the impact of those policies and measures that are firmly enshrined in legislation as of mid-2017. It provides a cautious assessment of where momentum from existing policies 
might lead the energy sector in the absence of any other impetus from the government. The

254 NPS scenario provides a sense of where today's policy ambitions seem likely to take the

255

Table 1. Overview of energy efficiency scenarios for room ACs

\begin{tabular}{|l|l|l|}
\hline S. No. & Scenario & Description \\
\hline 1 & $\begin{array}{l}\text { Business as } \\
\text { usual -- BAU }\end{array}$ & $\begin{array}{l}\text { Unit energy consumption (UEC) will remain at the } 2015 \\
\text { level. }\end{array}$ \\
\hline 2 & $\begin{array}{l}\text { Efficient room } \\
\text { AC (Economic) } \\
-- \text { EAC(E) }\end{array}$ & $\begin{array}{l}\text { Economic potential of UEC - efficiency of room AC unit will } \\
\text { improve by } 30 \%{ }^{43} \text {. }\end{array}$ \\
\hline 3 & $\begin{array}{l}\text { Efficient room } \\
\text { AC (Technical) } \\
-- \text { EAC (T) }\end{array}$ & $\begin{array}{l}\text { Technical potential of UEC - efficiency of room AC unit will } \\
\text { improve by } 60 \%{ }^{47} \text {. }\end{array}$ \\
\hline 4 & $\begin{array}{l}\text { Efficient room } \\
\text { AC (Economic) } \\
+ \text { Kigali } \\
\text { Amendment -- } \\
\text { EAC(E)+KA }\end{array}$ & $\begin{array}{l}\text { Economic potential of UEC along with additional energy } \\
\text { efficiency improvement of } 6 \% \text { due to low-GWP refrigerants } \\
\text { (i. e. HFC-32, HC-290). }\end{array}$ \\
\hline 5 & $\begin{array}{l}\text { Efficient room } \\
\text { AC (Technical) } \\
+ \text { Kigali } \\
\text { Amendment -- } \\
\text { EAC (T)+KA }\end{array}$ & $\begin{array}{l}\text { Technical potential of UEC along with additional energy } \\
\text { efficiency improvement of } 12 \% \text { due to low-GWP refrigerants } \\
\text { (i. e. HFC-32, HC-290). }\end{array}$ \\
\hline
\end{tabular}
energy sector. It incorporates not just the policies and measures that governments around the world have already put in place, but also the likely effects of announced policies, including the Nationally Determined Contributions (NDCs) made for the Paris Agreement (PA). The SDS scenario outlines an integrated approach to achieving internationally agreed objectives on climate change, air quality and universal access to modern energy. It represents a low carbon scenario consistent with a $2^{\circ} \mathrm{C}$ (i.e., $450 \mathrm{ppm}$ ) global warming target for this century, with considerably lower air pollution.

\section{RESULTS AND DISCUSSION}

265 We assess the energy sector and environmental co-benefits of the phase-down of HFCs used

266 in room ACs in the Chinese residential building sector under different scenarios using the methodology presented in Section 2. In the following sub-sections, we present the modeling 
results of the projection of room ACs in China at the national and provincial levels. In comparison to the BAU scenario, the electricity saving potentials under different scenarios have been estimated along with abatement potentials of GHGs, air pollutions and SLCPs until 2050.

\subsection{BAU projections of room ACs in China}

273 The total production volume, export volume, domestic retail volume of the Chinese room AC market from 2003 to 2017 is shown in Figure S1. The annual domestic sales volume of ACs has grown steadily, from 20 million units in 2003 to 88 million units in 2017, an increase by more than seven times ${ }^{11}$. The historical penetration of room ACs in Chinese provinces is taken from the National Bureau of Statistics of China ${ }^{11}$ as shown in Figure S3. The macroeconomic parameters (including GDP, population, etc.) are taken from NBSC (2019) ${ }^{11}$ whereas the urbanization rate at the national level is taken from UN DESA (2018) ${ }^{48}$. The historical data on average household sizes across the Chinese provinces is taken from the Institute of Population and Labor Economics of China ${ }^{49-51}$, whereas the future projections are taken from Zeng et al. (2008) ${ }^{52}$ due to the unavailability of recent household size projections at the provincial level. The CDD is the most common climatic index used to assess impacts on demand for space cooling services and reflects the deviation between the average temperature and a specified base temperature. The definition of CDDs involves determining a temperature threshold for AC employment, which varies due to differences in human physiological needs, energy supply, economic level, temperature characteristics and so on. For example, the threshold temperatures for CDD employment are $23{ }^{\circ} \mathrm{C}$ in $\operatorname{Spain}{ }^{53}, 22{ }^{\circ} \mathrm{C}$ in

289 Europe ${ }^{54}$, and $18.33{ }^{\circ} \mathrm{C}$ for the United States ${ }^{55}$. The base temperature used for China differs 290 across studies ${ }^{56-60}$ and is for this study taken to be $18^{\circ} \mathrm{C}$. The BizEE Degree Days Weather

291 Data for Energy Professionals is used to calculate the average CDDs during the last five years of each province. This data is taken to be the historical CDD for the year 2015 (see Table 
293 S2). The trend projection of CDDs for China at the national level until 2050 is obtained from

294 IEA (2018) ${ }^{2}$. Due to the lack of availability of provincial level projections of CDDs, we

295 assume the same trend applies to provinces as the national level of China.

296 Using the modeling framework discussed in the methodology section (Section 2), the results

297 indicate that the stock of room ACs in the residential building sector of China grows from

298568 million units in 2015 to 997 million units in 2030 and 1.1 billion units in 2050. In urban

299 China, room AC ownership per 100 households increases from 114 units in 2015 to 219 units

300 in 2030 and 225 units in 2050. The overall growth in the number of installed room ACs

301 remains relatively slow from 2040 onwards due to saturation amongst urban households. In

302 rural areas, room AC ownership per 100 households increases from 48 units in 2015 to 147

303 units in 2030 and 208 units in 2050 due to the increasing wealth of rural households. The

304 number of room ACs in urban China increases from 486 million units in 2015 to 793 million

305 units in 2030 and 919 million units by 2050. For rural China, the corresponding numbers are

30682 million units in 2015, 218 million units in 2040 and 208 million units in 2050 with a slight

307 decline in the last years due to rapid urbanization and a decreasing rural population in China.

308 Figure 1 presents the penetration of room ACs in China in the BAU scenario at the national,

309 urban and rural levels along with a comparison between the results based on this study our

310 estimates and those of other studies. The projections based on this study are very close to

311 O'Gresady and Narsipur (2018) ${ }^{60}$, Kalanki (2019) ${ }^{61}$ and IEA (2018) ${ }^{2}$ in 2030, whereas in

3122050 the deviation with IEA (2018) ${ }^{2}$ is larger primarily due to the difference in the macro-

313 economic assumptions. Detailed results on the penetration of residential ACs at the provincial

314 level for China are presented in Table S5 of the SI. 


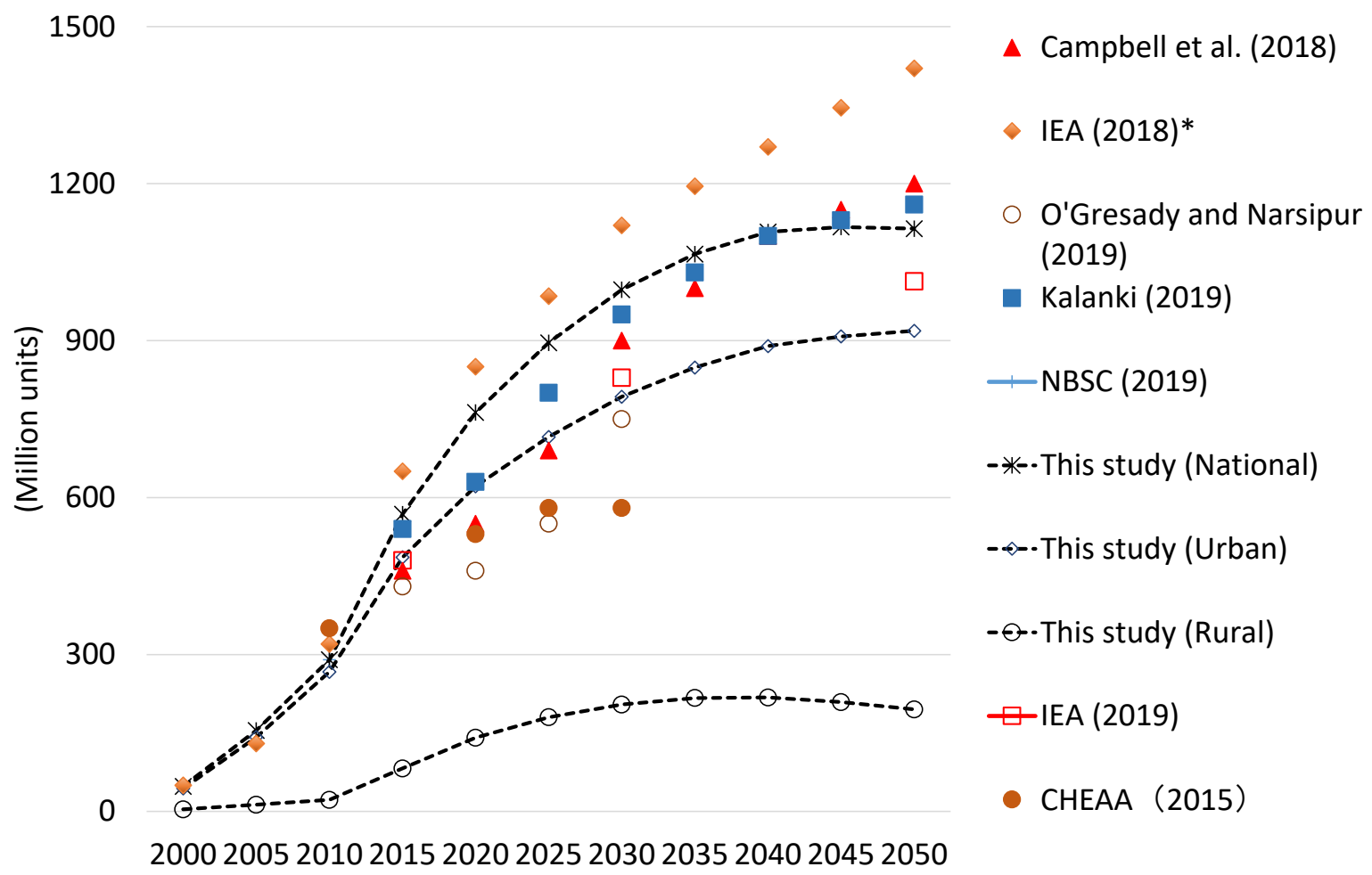

Figure 1. Comparison of room ACs stock under reference scenario with other studies

$317{ }^{*}$ IEA (2018) ${ }^{2}$ data extracted from Geman $(2018)^{64}$.

\section{3.2 Electricity consumption under BAU and alternative scenarios}

319 Figure 2 presents the technical and economic electricity savings potential when moving from 320 the BAU to alternative scenarios. As mentioned above, in the alternative scenarios we have

321 taken into account a) the technical/economic energy efficiency potential of room ACs, and b)

322 technical/economic efficiency improvement due to transition towards low-GWP alternatives

323 (i.e. HC-290) instead of high-GWP HFCs (i.e. HFC-410A/HFC-32). The technical losses in

324 the transmission and distribution (T\&D) of electricity have been taken into account ${ }^{65}$,

325 whereas non-technical losses (NTL) have not been included in estimating the electricity

326 saving potential. With reference to Lin et al. (2018) ${ }^{66}$, we set the technical losses at 5\%,

327 which means there is a 5\% difference between the generated capacity in power plants and

328 distributed capacity. The electricity consumption in the BAU scenario for space cooling in

329 the Chinese residential building sector is expected to reach 1314 TWh in 2050 as compared

330 to 503 TWh in 2015 and 961 TWh in 2030. The energy consumption trends reflect the huge

331 growth potential for space cooling in the Chinese residential building sector and are similar to 
332 the projected energy consumption growth for China in IEA (2010) ${ }^{68}$. In addition, the results

333 of the four alternative scenarios analyzed in this study indicate a significant electricity saving

334 potential through the adoption of energy-efficient ACs and transition towards low-GWP

335 refrigerants (see Table S9). The electricity consumption in 2050 is estimated at 368 TWh in

336 the EAC(T)+KA scenario (efficient AC along with low-GWP refrigerants (i.e. HC-290) using

337 technical energy efficiency potential), indicating an electricity saving potential of 996 TWh,

338 equivalent to about $4 \%$ of total Chinese building energy consumption in $2050{ }^{69}$.

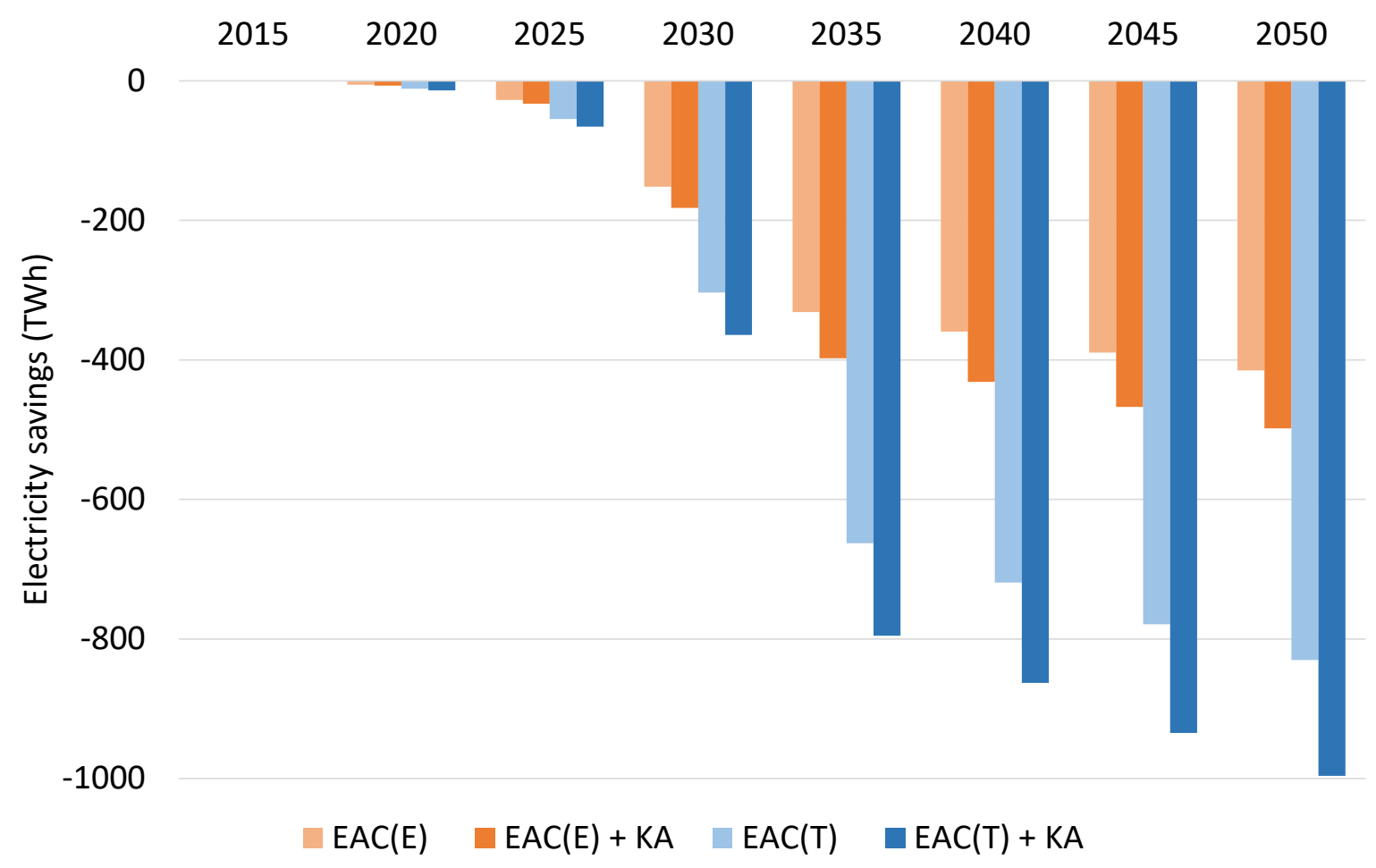

Figure 2. Electricity savings in the alternative scenarios as compared to the BAU scenario

342 The results presented in Table S9 exhibit the annual technical electricity saving potential in

343 the alternative scenarios relative to the BAU by the province in China. The technical

344 electricity saving potential under the KA is estimated at 364 TWh in 2030 and is limited by

345 assumptions about inertia in technology uptake. By 2050, no inertia in technology uptake

346 apply and the technical electricity saving potential is $996 \mathrm{TWh}$ when also considering a 
transition to low-GWP refrigerants under the KA. This is equivalent to avoiding 284 new

coal-fired power plants of 500 MW each assuming a capacity factor of $80 \%$.

349

350

351

352

353

354

355

356

357

358

359

360

361

362

363

364

365

366

367

368

369

370

371

\subsection{GHG mitigation due to HFC phase-down with enhanced energy efficiency}

The electricity-savings presented in Figure 2 and Table S9 can be converted to approximate reductions in $\mathrm{CO}_{2}$ emissions from electricity generation if we combine them with implied emission factors for $\mathrm{CO}_{2}$ that reflect the expected specific fuel mixes used in the power plant sector of China in the IEA’s World Energy Outlook 2018 current policies, new policies and sustainable development scenarios, respectively. Such implied emission factors are available from IIASA’s GAINS model in the timeframe to $2050{ }^{70}$. In addition, apart from direct savings in $\mathrm{CO}_{2}$ emissions from fuel combustion in power plants, there will also be savings in methane $\left(\mathrm{CH}_{4}\right)$ emissions in the upstream fossil fuel production sector. Noted that $\mathrm{CH}_{4}$ emissions from coal mining in China have risen despite stricter government regulations that aimed to curb the greenhouse gas emissions ${ }^{87}$. The implied emission factor in $\mathrm{kt}^{\mathrm{CH}_{4}}$ per $\mathrm{Mt}$ coal produced from Chinese coal mines and the corresponding implied emission factors per PJ oil and gas produced, were taken from IIASA's GAINS model. Estimated $\mathrm{CH}_{4}$ emissions per TWh electricity saved take account of expected changes over time in the fuel mix of electricity production as represented in the different IEA-WEO 2018 scenarios. Except for special illustration, the emission factors used in emissions analysis in this article are taken from the new policies scenario (NPS) of the IEA’s World Energy Outlook 2018.

In the BAU scenario, HFC emissions associated with room ACs increased from $115 \mathrm{Mt}$ $\mathrm{CO}_{2}$ eq in 2015 to $125 \mathrm{Mt} \mathrm{CO}_{2}$ eq in 2030 and $133 \mathrm{Mt} \mathrm{CO}_{2}$ eq in 2050 (see Section S4), whereas $\mathrm{CO}_{2}$ emissions due to electricity consumption reach $359 \mathrm{Mt}$ in 2050 as compared to $164 \mathrm{Mt}$ in 2015 and $292 \mathrm{Mt}$ in 2030. In addition, the upstream $\mathrm{CH}_{4}$ emissions associated with the electricity consumption are estimated at $32 \mathrm{Mt} \mathrm{CO} \mathrm{CO}_{2} \mathrm{eq} 2050$ as compared to $27 \mathrm{Mt}$ $\mathrm{CO}_{2}$ eq in 2015 and $37 \mathrm{Mt} \mathrm{CO}_{2}$ eq in 2030. Hence, total $\mathrm{CO}_{2}$ eq emissions associated with 
$373 \mathrm{CO}_{2}$ eq in 2030 and $524 \mathrm{Mt} \mathrm{CO}$ eq in 2050 using the implied emission factor from the IEA-

374 WEO 2018 NPS scenario. Figure 3 presents the results of GHG mitigation from the Chinese

375 residential building sector under the alternative scenarios in 2030 and 2050, respectively, as

376 compared to the BAU scenario.

377 In 2050, under $\mathrm{EAC}(\mathrm{T})+\mathrm{KA}$ scenario, $\mathrm{CO}_{2}$ mitigation from electricity savings is estimated at 378272 Mt using NPS variants, whereas GHG mitigation due to transitioning towards low-GWP

379 refrigerants reaches $122 \mathrm{Mt} \mathrm{CO}_{2} \mathrm{eq}$, and the GHG reduction from the upstream $\mathrm{CH}_{4}$

380 emissions due to electricity savings is estimated at $25 \mathrm{Mt} \mathrm{CO}_{2}$ eq. Therefore, the total GHG

381 mitigation potential for the Chinese residential building sector when accounting for both the

382 electricity savings and the transition to low-GWP refrigerants is estimated at $420 \mathrm{Mt} \mathrm{CO}_{2} \mathrm{eq}$

383 in 2050. This is equivalent to approximately $10 \%$ of the total building sector $\mathrm{CO}_{2}$ emissions

384 and nearly $3 \%$ of the total $\mathrm{CO}_{2}$ emissions in China in 2050 69, 71,72 .

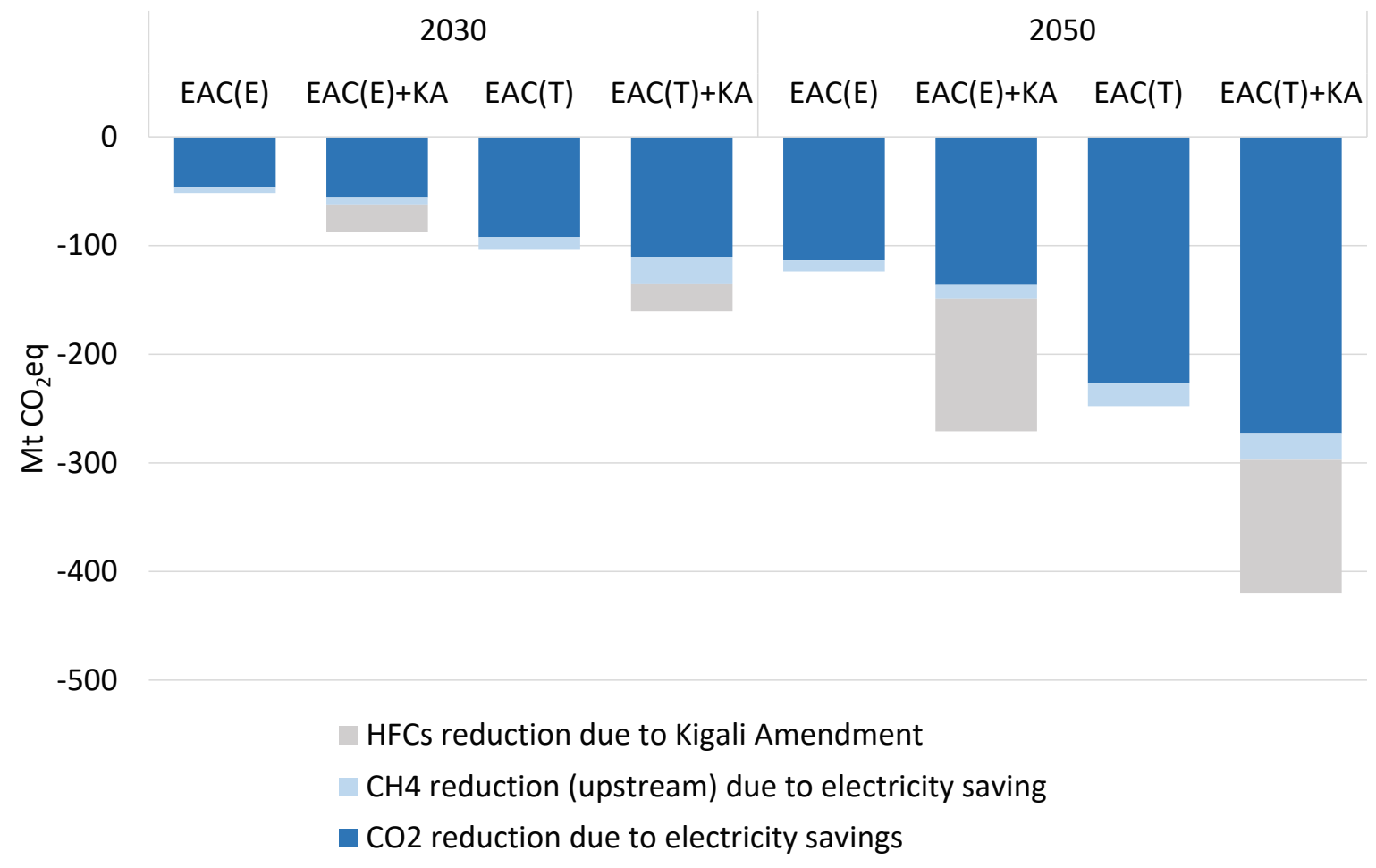

Figure 3. GHG mitigation in the alternative scenarios 
388

389

390

391

392

393

394

395

396

397

398

399

400

401

402

403

404

405

406

407

408

409

410 411 from refrigerant emissions together with the $\mathrm{CO}_{2}$ mitigation from electricity-savings varies

412 significantly across provinces. Most provinces with large GHG mitigation potential are

Figure 4 presents $\mathrm{CO}_{2}$ mitigation in the alternative scenarios due to electricity savings induced by the HFC phase-down and under assumptions of technical and economic energy efficiency improvements, respectively, as well as implied emission factors from the CPS, NPS and SDS variants, respectively. Relative to the BAU scenario, the $\mathrm{CO}_{2}$ mitigation potentials under the KA scenario and assuming a technical energy efficiency improvement potential are estimated at $117 \mathrm{Mt} \mathrm{CO}{ }_{2} \mathrm{eq}$ in 2030 and $402 \mathrm{Mt} \mathrm{CO}_{2} \mathrm{eq}$ in 2050 using implied emission factors from the IEA-WEO 2018 CPS scenario. The $\mathrm{CO}_{2}$ mitigation potentials due to transitioning towards low-GWP HFC alternatives for meeting the KA targets under the

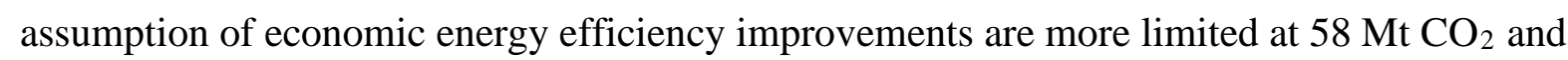
$201 \mathrm{Mt} \mathrm{CO}$, respectively, in 2030 and 2050, using CPS variants. As expected, reductions in $\mathrm{CO}_{2}$ emissions using the NPS and SDS variants are lower as compared to the CPS in all scenarios presented in Figure 4, primarily due to higher penetration of clean fuels (gas, renewables etc.) and energy efficiency measures in the power sector. The range is a reflection of the different degrees of decarbonization of the energy system inherent in the CPS, NPS, and SDS as specified in the IEA-WEO 2018. In the CPS, the future electricity supply relies more heavily on fossil fuels and less on renewables than in the SDS, promoting $\mathrm{CO}_{2}$ mitigation from electricity saving to be larger in the current policies scenario. The electricitysavings can be reaped when the air-conditioning equipment that uses alternative technologies to HFCs are properly installed and maintained, as the $\mathrm{CO}_{2}$ reductions of these electricitysavings correspond to a significant fraction of total GHG emission reductions from highGWP HFC (e.g. HFC-410A) phase-down. GHG mitigation at the provincial level due to the enhanced energy efficiency of room ACs using low-GWP refrigerants and substitution of high-GWP refrigerants is presented in Figure S7 of the SI. It is observed that GHG mitigation 
413 concentrated in Hot Summer and Warm Winter or Hot Summer and Cold Winter climate

414 zones, such as Guangdong, Jiangsu, Zhejiang, and Hubei provinces due to the higher

415 temperature and longer duration of summer than other provinces (Table S9). This kind of

416 climate zone division is consistent with the Chinese architectural climate zone planning map

417 in the Code for Design of Civil Buildings (GB50352-2005) ${ }^{75}$.

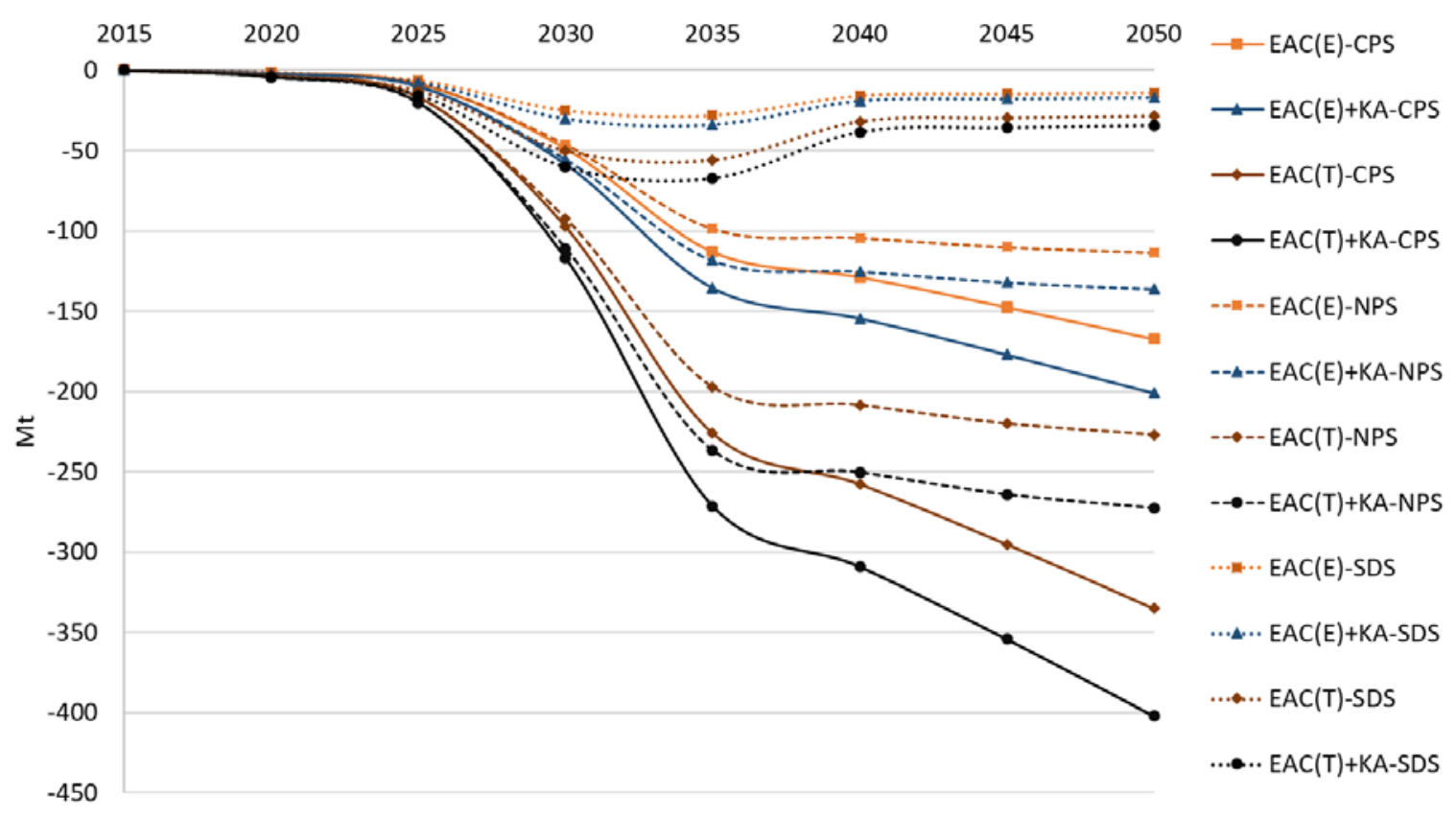

419 Figure 4. Annual $\mathrm{CO}_{2}$ mitigation in alternative scenarios relative to the BAU scenario due to 420 electricity savings

421 3.4 Air pollutant and SLCP emissions due to HFC phase-down with enhanced energy 422 efficiency

423 Another major environmental benefit of reduced electricity demand for cooling technologies

424 is improved air quality and fewer related adverse health and ecosystem effects ${ }^{73,74}$. The

425 electricity generation units that respond to this increased demand are major contributors to

$426 \mathrm{SO}_{2}$ and $\mathrm{NO}_{\mathrm{x}}$, both of which have direct impacts on public health, and contribute to the

427 formation of secondary pollutants including ozone and $\mathrm{PM}_{2.5}$. In 2015, residential space

428 cooling was responsible for $9 \%$ of global $\mathrm{SO}_{2}$ emissions from the power sector and $8 \%$ of

$429 \mathrm{NO}_{\mathrm{x}}$ and $\mathrm{PM}_{2.5}$ emissions from the power sector ${ }^{2}$. 
430 Figure 5 presents the reductions in air pollutants and SLCPs emissions in alternative

431 scenarios due to the HFC phase-down with associated improvements in the technical and

432 economic energy efficiency potential of room ACs relative to the BAU scenario. According

433 to the projection of this study, in 2050, the air pollutants reduction potential in EAC(T)+KA

434 scenario is estimated at $133 \mathrm{kt} \mathrm{SO}_{2}, 227 \mathrm{kt} \mathrm{NO}_{\mathrm{x}}, 39 \mathrm{kt} \mathrm{PM} 2.5$ using the implied emission

435 factors obtained from IEA-WEO 2018 CPS scenario as shown in Figure 5 (a-c). Figure 5 (d-

436 e) indicates the annual reductions of SLCPs, including BC, and OC, in the alternative

437 scenarios due to electricity-savings associated with HFC phase-down when assuming

438 technical and economic energy efficiency improvements in cooling technologies. In 2050, the

439 SLCPs reduction potential in EAC(T)+KA scenario is $0.6 \mathrm{kt} \mathrm{BC,} 2.8 \mathrm{kt}$ OC with CPS

440 variants.

441 


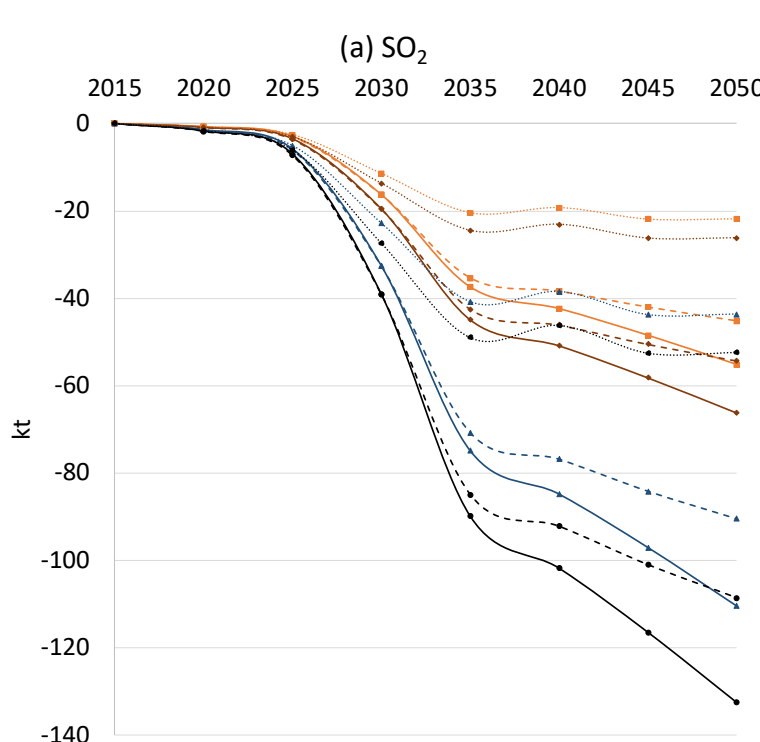

$-140$

(d) $\mathrm{BC}$

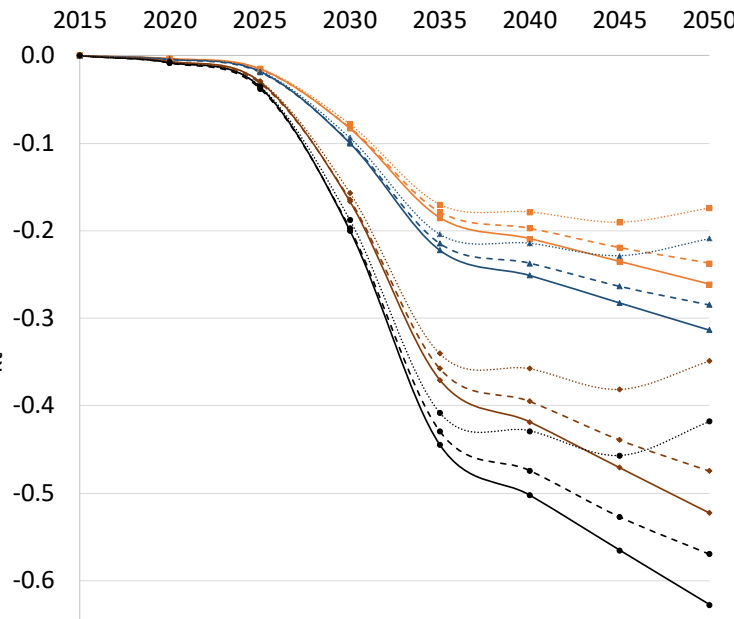

443 Figure 5. Annual air pollutants and SLCPs emission reductions in the alternative scenarios relative to the BAU scenario (b) $\mathrm{NO}_{x}$

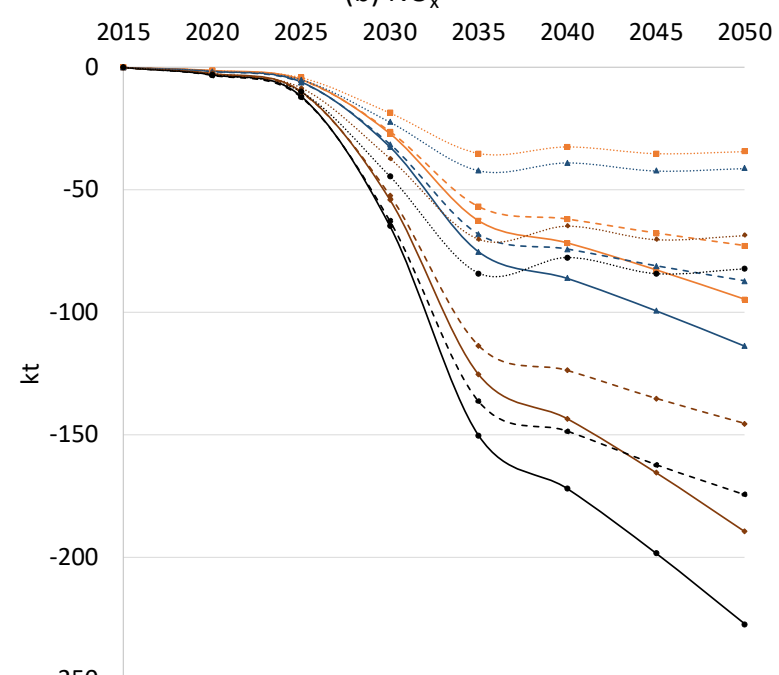

$-250$

(e) OC

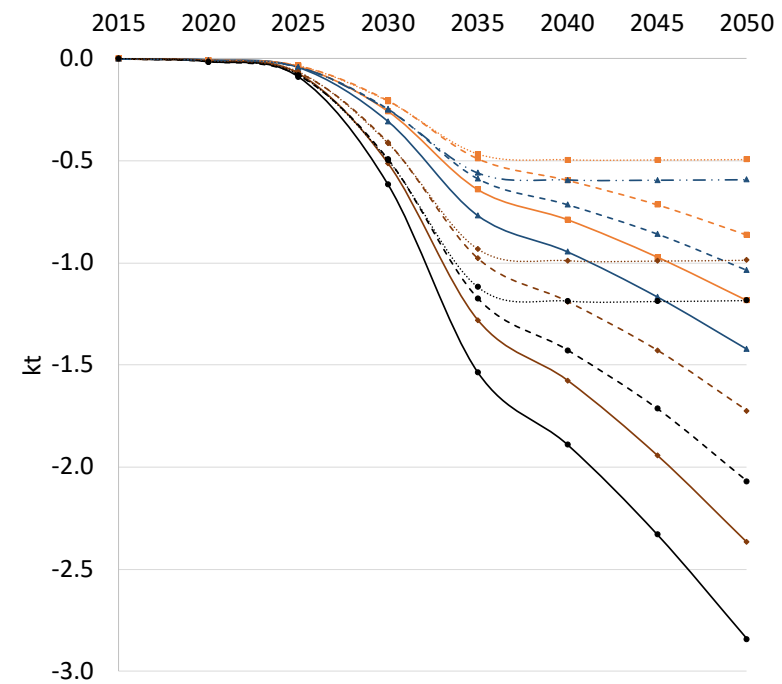

(c) $\mathrm{PM}_{2.5}$

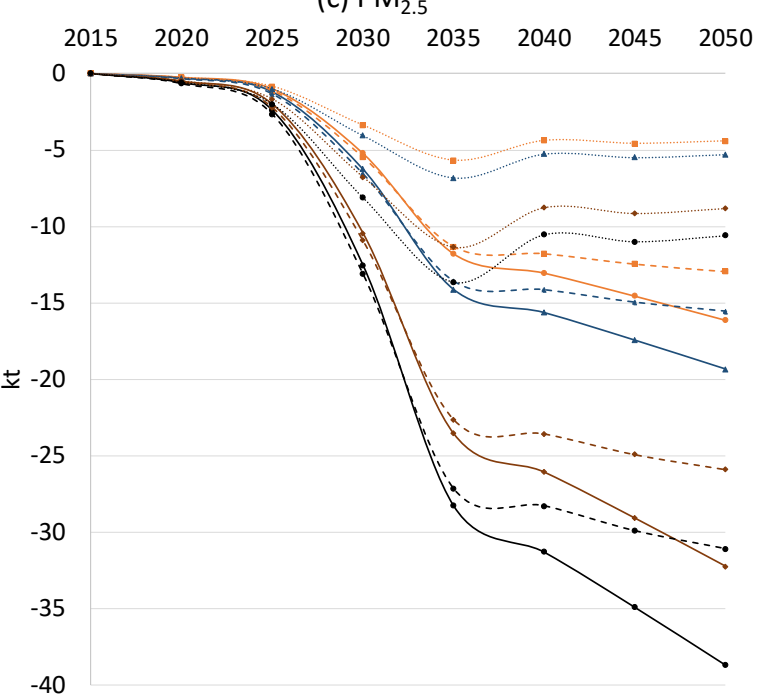

-EAC(E)-CPS

- $\mathrm{EAC}(\mathrm{E})+\mathrm{KA}-\mathrm{CPS}$

$\rightarrow$-EAC(T)-CPS

$\rightarrow$ EAC(T)+KA-CPS

- - EAC(E)-NPS

- - EAC(E)+KA-NPS

- -EAC(T)-NPS

$\cdots$ EAC(T)+KA-NPS

- EAC(E)-SDS

- EAC(E)+KA-SDS

- EAC(T)-SDS

- EAC(T)+KA-SDS 


\subsection{Policy implications and future directions of research}

445 In the last two decades, China had the fastest growth in space cooling energy consumption 446 worldwide, driven by increasing income and growing demand for thermal comfort. In this study, we model future penetration of room air-conditioners (ACs) in the residential building sector of China at the provincial level, with consideration of urban-rural heterogeneities. Using market data and considering factors such as expected changes in climatic conditions and income, we first develop a business-as-usual (BAU) scenario for the future penetration of room ACs by 2050 in China. We then estimate the associated impacts on electricity demand considering the scopes for technical and economic energy efficiency improvements in room ACs and the energy efficiency benefits associated with the transition to low-GWP

454 refrigerants.

The results indicate that increasing income, growing demand for thermal comfort and warmer climate conditions, are expected to drive an increase in the stock of room ACs in China from 568 million units in 2015 to 997 million units in 2030 and 1.1 billion units in 2050. In urban China, room AC ownership per 100 households is expected to increase from 114 units in 2015 to 219 units in 2030 and 225 units in 2050, with slow growth after 2040 due to the saturation of room ACs in the urban households of China. Ownership of room ACs per 100 households in rural China increases from 48 units in 2015 to 147 units in 2030 and 208 units in 2050. The total number of room ACs in rural China increases from 82 to 218 million units between 2015 and 2040 and then decreases slightly to 208 million units by 2050 primarily due to rapid urbanization and decreasing rural population. Therefore, strong efficiency improvement policies can make a significant dent in the energy consumption of space cooling in the Chinese residential building sector. Currently, the AC 
average energy efficiency of ACs sold in the market is only $40 \%$ of the best available

470

471

472

473

474

475

476

477

478

479

480

481

482

483

484

485

486

487

488

489

490

491

492

493

efficiency level and $80 \%$ of the market average available efficiency ${ }^{8}$. Without strong policy incentives to improve the energy efficiency of ACs, the energy consumption will expand to 1314 TWh in 2050 as compared to 961 TWh in 2030 and 503 TWh in 2015. The alternative scenarios analyzed in this study indicate a remarkable electricity saving potential through the enhanced energy efficiency of room ACs using low-GWP refrigerants (i.e. HFC-290). The electricity consumption in 2050 is estimated at 368 TWh using a technical energy efficiency potential, indicating an annual electricity saving potential of $996 \mathrm{TWh}$, which is equivalent to about $4 \%$ of expected total building energy consumption in $2050{ }^{69}$.

Phasing down the use of high-GWP refrigerants provides a great opportunity for policymakers to move to a low-carbon society in China. Our results indicate that the BAU emissions of HFCs from the room AC sector are expected to increase from 115 to $125 \mathrm{Mt}$ $\mathrm{CO}_{2}$ eq between 2015 and 2030 and reaching $133 \mathrm{Mt} \mathrm{CO}$ eq in 2050, prior to the commitments made by China under the Kigali Amendment (KA) to the Montreal Protocol. The growth is mainly driven by increasing penetration of room ACs in urban and rural households, which in turn is driven by an expected increase in per capita wealth in China, a warmer future climate, combined with the effect of replacing HCFCs with HFCs in accordance with the 2007 revision of the Montreal Protocol. Transitioning to low-GWP refrigerants in room ACs in compliance with the KA, the residential building sector of China is expected to reduce HFC emissions by $20 \%$ in 2030 and $92 \%$ in 2050 as compared to the BAU scenario.

The potential for improved energy efficiency due to the adoption of low-GWP refrigerants (HC-290) and energy efficiency improvements of the AC systems (i.e. efficient compressors, heat exchangers, etc.) can significantly reduce electricity consumption from room ACs in the residential building sector. The cumulative $\mathrm{CO}_{2}$ mitigation due to these energy efficiency 
494 improvements makes up 2.6\% of total $\mathrm{CO}_{2}$ emissions expected to be emitted in China over 495 the period 2020 to 2050.

496 China can deliver significant energy savings and associated reductions in GHG and air

497 pollution emissions in the building sector by developing and implementing a comprehensive

498 national policy framework, including legislation and regulation, information programs and

499 incentives for industry. Energy efficiency and refrigerant standards for room AC installations

500 should be an integral part of such a framework. Training and awareness raising can also

501 ensure proper installation, operation and maintenance of air conditioning equipment and

502 systems, and mandatory good practice with leakage control of the refrigerant during the use

503 and end-of-life recovery. Improved data collection, research and co-operation with

504 manufacturers can equally help to identify emerging trends, technology needs and energy

505 efficiency opportunities that enable sustainable cooling. Although this article systematically

506 analyzes the co-benefits of space cooling in the Chinese residential building sector, the model

507 can be extended in the future to also consider consumer behavior influence and future trends

508 in the air-conditioning industry.

509 Acknowledgments

510 This work was developed during the time of Young Scientists Summer Program (YSSP) at

511 the International Institute for Applied Systems Analysis (IIASA), Laxenburg (Austria) with

512 the financial support from the National Natural Science Foundation of China. This study is

513 funded by the Natural Science Foundation of China (71904007; 71773006).

\section{Supporting Information}

515 Additional information for methods; Additional data and results at the provincial level with

516 rural and urban disparity, Additional description of different refrigerants used in ACs along

517 with baseline and HFC phase-down schedule of Article 5 countries of the Montreal Protocol; 
518 Additional results on air pollutants, SLCPs, as well as GHG mitigation at the provincial level

519 due to enhanced ACs system efficiency and the substitution of high-GWP refrigerants.

\section{References}

521

522

523

524

525

526

527

528

529

530

531

532

533

534

535

536

537

538

539

540

541

1. EIA (Energy Information Administration, U.S.). International Energy Outlook. 2016, DOE/EIA-0484(2016). https://www.eia.gov/outlooks/ieo/pdf/buildings.pdf (accessed October $\left.5^{\text {th }}, 2019\right)$.

2. IEA (International Energy Agency). The Future of Cooling: Opportunities for energyefficient air conditioning, 2018.

https://webstore.iea.org/download/direct/1036?fileName=The_Future_of_Cooling.pdf (accessed September $27^{\text {th }}$, 2019).

3. IEA (International Energy Agency). Transition to Sustainable Buildings: Strategies and Opportunities to 2050, 2013.

https://www.iea.org/media/training/presentations/etw2014/publications/Sustainable_Build ings_2013.pdf (accessed October 5th, 2019).

4. Goetzler, W.; Guernsey, M.; Young, J.; Fuhrman, J.; Abdelaziz, O. The Future of Air Conditioning for Buildings. 2016.

https://www.energy.gov/sites/prod/files/2016/07/f33/The\%20Future\%20of\%20AC\%20Re port\%20-\%20Full\%20Report_0.pdf (accessed October $5^{\text {th }}$, 2019).

5. Urge-Vorsatz, D.; Petrichenko, K.; Staniec, M.; Eom, J. Energy use in buildings in a long-term perspective. Current Opinion in Environmental Sustainability 2013, 5(2), 141151.

6. Velders, G.J.M.; Fahey, D.W.; Daniel J.S.; Andersen, S.O.; McFarland, M. Future atmospheric abundances and climate forcings from scenarios of global and regional hydrofluorocarbon (HFC) emissions. Atmospheric Environment 2015, 123, 200-209. 
542 7. Galka, M.D.; Lownsbury, J.M.; Blowers, P. Greenhouse Gas Emissions for Refrigerant

543 Choices in Room Air Conditioner Units. Environmental Science and Technology 2012, $544 \quad 46,12977-12985$.

545 8. IEA (International Energy Agency). The Future of Cooling in China, 2019.

546 https://webstore.iea.org/download/direct/2808?fileName=The_Future_of_Cooling_in_Chi

$547 \quad$ na.pdf (accessed September $27^{\text {th }}, 2019$ ).

548 9. Zhou, N.; Fridley, D.; McNeil, M.; Zheng, N.; Letschert, V.; Ke, J. Analysis of potential

549 energy saving and $\mathrm{CO}_{2}$ emission reduction of home appliances and commercial

$550 \quad$ equipments in China. Energy Policy 2011, 39, 4541-4550.

551 10. Fridley, D.G.; Rosenquist, G.; Lin, J.; Li, A.; Xin, D.; Cheng, J. Technical and Economic

552 Analysis of Energy Efficiency of Chinese Room Air Conditioners. Lawrence Berkeley

$553 \quad$ National Laboratory Series Report 2001, LBNL-45550.

$554 \quad$ https://escholarship.org/uc/item/9cw020f8 (accessed October $5^{\text {th }}, 2019$ ).

555 11. NBSC (National Bureau of Statistics of China). Annual national data by province, 2019.

$556 \quad$ http://data.stats.gov.cn/english/easyquery.htm?cn=E0103 (assessed 26 ${ }^{\text {th }}$ Sep., 2019).

557 12. Zhao, C.; Graham, J.M. The PRC’s Evolving Standards System: Institution and Strategy.

$558 \quad$ Asia Policy 2006, 2(1), 63-88.

13. CNIS (China National Institute of Standardization). The minimum allowable values of the energy efficiency and energy efficiency grades for room air conditioners. GB12021.32004, 2004. http://www.doc88.com/p-6292340608677.html (accessed September $27^{\text {th }}$, 2019).

14. CNIS (China National Institute of Standardization). The minimum allowable values of the energy efficiency and energy efficiency grades for room air conditioners. GB 214552008, 2008. http://www.doc88.com/p-349518814350.html (accessed September 27 ${ }^{\text {th }}$, 2019). 
15. CNIS (China National Institute of Standardization). The minimum allowable values of the energy efficiency and energy efficiency grades for variable speed room air conditioners. GB12021.3-2010, 2010. http://www.doc88.com/p-99414654642.html (accessed September $\left.27^{\text {th }}, 2019\right)$.

16. CNIS (China National Institute of Standardization). The minimum allowable values of the energy efficiency and energy efficiency grades for variable speed room air conditioners. GB21455-2013, 2013. http://www.doc88.com/p-9965080278941.html (accessed September $27^{\text {th }}, 2019$ ).

17. Cardoso, R.B.; Nogueira, H.L.A.; de Souza, E.P.; Haddad, J. An assessment of energy benefits of efficient household air-conditioners in Brazil. Energy Efficiency 2012, 5(3), 433-446.

18. Waite, M.; Cohen, E.; Torbey, H.; Piccirilli, M.; Tian, Y.; Modi V. Global trends in urban electricity demands for cooling and heating. Energy 2017, 127, 786-802.

19. Serrano, S.; Urge-Vorsatz, D.; Barreneche, C.; Palacios, A.; Cabeza, L.F. Heating and cooling energy trends and drivers in Europe. Energy 2017, 119, 425-434.

20. Jakubcionis, M.; Carlsson J. Estimation of European Union residential sector space cooling potential. Energy Policy 2017, 101, 225-235.

21. Urge-Vorsatz, D.; Cabeza, L.F.; Serrano, S.; Barreneche, C.; Petrichenko, K. Heating and cooling energy trends and drivers in buildings. Renewable and Sustainable Energy Reviews 2015, 41, 85-98.

22. WMO (World Meteorological Organization). Scientific Assessment of Ozone Depletion 2018: Executive Summary. https://www.esrl.noaa.gov/csd/assessments/ozone/2018/executivesummary.pdf (accessed October $30^{\text {th }}, 2019$ ) 
591

592

593

594

595

596

597

598

599

600

601

602

603

604

605

606

607

608

609

610

611

612

613

614

615

23. Phadke, A.; Abhyankar, N.; Shah, N. Avoiding 100 new power plants by increasing efficiency of room air conditioners in India: Opportunities and challenges, Environmental Energy Technologies Division. Lawrence Berkeley National Laboratory Series Report 2014, LBNL-6674E. http://eta-publications.lbl.gov/sites/default/files/lbnl-6674e.pdf (accessed October $\left.8^{\text {th }}, 2019\right)$.

24. Li, Z.; Bie P.; Wang, Z.; Zhang, Z.; Jiang, H.; Xu W.; Zhang, J.; Hu, J. Estimated HCFC22 emissions for 1990-2050 in China and the increasing contribution to global emissions. Atmospheric Environment 2016, 132, 77-84.

25. Liu, L.; Dou, Y.; Yao, B.; Bie, P.; Wang, L.; Peng, M.; Hu, J. Historical and projected HFC-410A emission from room air conditioning sector in China. Atmospheric Environment 2019, 212, 194-200.

26. Wang, Z.; Fang, X.; Li, L.; Bie, P.; Li, Z.; Hu, J.; Zhang, B.; Zhang, J. Historical and projected emissions of HCFC-22 and HFC-410a from China's room air conditioning sector. Atmospheric Environment 2016, 132, 30-35.

27. Fang, X.; Velders, G.J.M.; Ravishankara, A.R.; Molina, M.J.; Hu, J.; Prinn, R.G. Hydrofluorocarbon (HFC) Emissions in China: An Inventory for 2005-2013 and Projections to 2050. Environmental Science and Technology 2016, 50 (4), 2027-2034.

28. Purohit, P.; Höglund-Isaksson, L. Global emissions of fluorinated greenhouse gases 2005-2050 with abatement potentials and costs. Atmospheric Chemistry and Physics 2017, 17, 2795-2816.

29. UNEP (United Nations Environment Programme). Report of the task force on HCFC issues and emissions re-duction benefits arising from earlier HCFC phase-out and other practical measures, Nairobi, 2007.

30. Montzka, A.D.; Dutton, G.S.; Yu, P.; Ray, E.; Portmann, R.W.; Daniel, J.S.; Kuijpers, L.,; Hall, B.D.; Mondeel, B.; Siso, C.; Nance, J.D.; Rigby, M.; Manning, A.J.; Hu, L.; 
Moore, F.; Miller, B.R.; Elkins, J.W. An unexpected and persistent increase in global emissions of ozone-depleting CFC-11. Nature 2018, 557, 413-417.

31. UNEP (United Nations Environment Programme). Handbook for the Montreal Protocol on Substances that Deplete the Ozone Layer, 9th Edition, 2012.

32. UNEP (United Nations Environment Programme). Further Amendment of the Montreal Protocol: Submitted by the Contact group on HFCs. Twenty-Eighth Meeting of the Parties to the Montreal Protocol on Substances that Deplete the Ozone Layer, 2016. Kleefeld, J. Cost estimates of the Kigali Amendment to phase-down hydrofluorocarbons. Environmental Science and Policy 2017, 75, 138-147. https://www.sciencedirect.com/science/article/pii/S146290111730120X (accessed September $27^{\text {th }}$, 2019).

34. Purohit P.; Höglund-Isaksson L.; Wagner, F. Impacts of the Kigali Amendment to phasedown hydrofluorocarbons (HFCs) in Asia. IIASA Report, 2018, http://pure.iiasa.ac.at/id/eprint/15274/1/Impacts\%2520of\%2520the\%2520Kigali\%2520A mendment.pdf (accessed October $8^{\text {th }}$, 2019).

35. Mcneil, M. A.; Letschert, V. E. Future Air-Conditioning Energy Consumption in Developing Countries and what can be done about it: The Potential of Efficiency in the Residential Sector. Lawrence Berkeley National Laboratory Series Report, 2008. https://escholarship.org/uc/item/64f9r6wr (accessed September 27 $7^{\text {th }}, 2019$ ). residential cooling energy demand to climate change. Energy 2003, 28(9), 941-951. and consequent $\mathrm{CO}_{2}$ emissions to minimize health risks due to climate change in India. Environmental Science \& Policy 2010, 13(8), 702-712. 
641

642

643

644

645

646

647

648

649

650

651

652

653

654

655

656

657

658

659

660

661

662

663

664

665

38. Isaac, M.; Vuuren, D. P. V. Modeling global residential sector energy demand for heating and air conditioning in the context of climate change. Energy Policy 2009, 37(2), 507521.

39. Kitous, A.; Després, J. Assessment of the impact of climate change on residential energy demand for heating and cooling. Joint Research Center Science for Policy Report 2018, JRC 108692.

http://publications.jrc.ec.europa.eu/repository/bitstream/JRC110191/jrc_technical_report_ peseta3_energy_20180117.pdf (accessed October $2^{\text {nd }}, 2019$ ).

40. Li, Y.; Fei, Y.; Zhang, X.B.; Qin, P. Household appliance ownership and income inequality: Evidence from micro data in China. China Economic Review 2019, 56, 101309.

41. Mendes, G.; Feng, W.; Stadler, M.; Steinbach, J.; Lai, J.; Zhou, N.; Marnay, C.; Ding, Y.; Zhao, J.; Tian, Z.; Zhu, N. Regional analysis of building distributed energy costs and $\mathrm{CO}_{2}$ abatement: A U.S.-China comparison. Energy and Buildings 2014, 77, 112-129.

42. Guo F.; Pachauri, S.; Cofala, J. Cost-effective subsidy incentives for room air conditioners in China: An analysis based on a McFadden-type discrete choice model. Energy policy 2017, 110, 375-385.

43. Shah, N.; Wei, M.; Letschert, M.; Phadke A. Benefits of Leapfrogging to Superefficiency and Low Global Warming Potential Refrigerants in Room Air Conditioning. Lawrence Berkeley National Laboratory Series Report 2015.

https://ies.lbl.gov/sites/default/files/lbnl-1003671.pdf. (accessed September 27 ${ }^{\text {th }}, 2019$ ).

44. Shah, N.; Waide, P.; Phadke, A. Cooling the planet: opportunities for deployment of superefficient room air conditioners. Lawrence Berkeley National Laboratory Series Report 2013.

http://hydrocarbons21.com/files/1349_Final\%20SEAD\%20Room\%20AC\%20Report.pdf 
45. IPCC (Intergovernmental Panel on Climate Change). Climate Change 2014: Synthesis Report. Contribution of Working Groups I, II and III to the Fifth Assessment Report of the Intergovernmental Panel on Climate Change, 2014. https://archive.ipcc.ch/pdf/assessment-report/ar5/syr/SYR_AR5_FINAL_full_wcover.pdf (accessed September $27^{\text {th }}$, 2019).

46. Amann, M.; Bertok, I.; Borken-Kleefeld, J.; Cofala, J.; Heyes, C.; Höglund-Isaksson, L.; Modeling and policy applications. Environmental Modelling \& Software 2011, 26(12), 1489-1501.

47. Purohit, P.; Höglund-Isaksson, L.; Dulac, J.; Shah, N.; Wei, M.; Rafaj, P.; and Schöpp, of hydrofluorocarbons, Atmospheric Chemistry and Physics Discussions 2020, https://doi.org/10.5194/acp-2020-193 (accessed March 13 $\left.{ }^{\text {th }}, 2020\right)$.

48. UN DESA (United Nations, Department of Economic and Social Affairs). World Urbanization Prospects: The 2018 Revision, Online Edition, 2018. https://population.un.org/wpp/ (accessed September $27^{\text {th }}$, 2019).

49. CASS IPLE (Chinese Academy of Social Sciences, Institute of Population and Labor Economics). Almanac of China’s Population, 2001.

50. CASS IPLE (Chinese Academy of Social Sciences, Institute of Population and Labor Economics). Almanac of China’s Population, 2006. Economics). Almanac of China’s Population, 2011. 
690

691

692

693

694

695

696

697

698

699

700

701

702

703

704

705

706

707

708

709

710

711

712

713

52. Zeng, Y.; Wang, Z.; Jiang, L.; Gu, D. Future trend of family households and elderly living arrangement in China. Genus 2008, 64(1-2), 9-36.

http://opensky.ucar.edu/islandora/object/articles\%3A10265/datastream/PDF/download/cit ation.pdf (accessed September $\left.27^{\text {th }}, 2019\right)$.

53. Labandeira, X.; Labeaga, J.M.; López-Otero, X. Estimation of elasticity price of electricity with incomplete information. Energy Economics 2012, 34, 627-633.

54. Eskeland, S.G.; Mideksa, K.T. Electricity demand in a changing climate. Mitigation and Adaptation Strategies for Global Change 2010, 15, 877-897.

55. Alberini, A.; Filippini, M. Response of residential electricity demand to price: the effect of measurement error. Energy Economics 2011, 33, 889-895.

56. Cao, J.; Qiu, C.; Liu, H.B.; Shi, Z.J.; Dong, X.G. Spatiotemporal distribution of heating and cooling degree days in Shandong Province. Meteorological Monthly 2013, 39, 94100.

57. Shi, Y.; Gao, X.J.; Xu, Y.; Giorgi, F.; Chen, D.L. Effects of climate change on heating and cooling degree days and potential energy demand in the household sector of China. Climate Research 2016, 67, 135-149.

58. Xie, Z.; Su, D.; Yu, H.; Li, D.; Yu, L.; Hu, T. Characteristics of heating degree days and cooling degree days in Beijing. Journal of Applied Meteorological Science 2007, 18, 232-236. (in Chinese)

59. You, Q.; Fraedrich, K.; Sielmann, F.; Min, J.; Kang, S.; Ji, Z.; Zhu, X.; Ren, G. Present and projected degree days in china from observation, reanalysis and simulations. Climate Dynamics 2014, 43(5-6), 1449-1462.

60. Shi, Y.; Wang, G.; Gao, X.; Xu, Y. Effects of climate and potential policy changes on heating degree days in current heating areas of China. Scientific Reports 2018, 8, 10211. 
61. O'Gresady, E.; Narsipur, S. Cooling is warming the planet, but market failures are freezing the AC industry's innovation. Rocky Mountain Institute, 2018. https://www.greenbiz.com/article/cooling-warming-planet-market-failures-are-freezingac-industrys-innovation (accessed September 27 ${ }^{\text {th }}, 2019$ ).

62. Kalanki, A. Transforming the global comfort cooling market: China’s opportunity for economic and climate leadership. Rocky Mountain Institute, 2019. https://www.greenbiz.com/article/transforming-global-comfort-cooling-market-chinasopportunity-economic-and-climate (accessed September $27^{\text {th }}, 2019$ ).

63. Campbell, I.; Kalani, A.; Sachar, S. Solving he global cooling challenge: How to counter the climate threat from room air conditioners. Global cooling Prize, 2018. https://rmi.org/wp-content/uploads/2018/11/Global_Cooling_Challenge_Report_2018.pdf (accessed September $27^{\text {th }}$, 2019).

64. Geman, B. Next climate challenge: A/C demand expected to triple. Axios, 2018. https://www.axios.com/cooling-the-earth-without-cooking-it-3a9b3cd1-b6fb-4efa-aa70cacf0389c530.html (accessed September 27 ${ }^{\text {th }}, 2019$ ).

65. Brander, M.; Sood, A.; Wylie, C.; Haughton, A.; Lovell, J. Electricity-specific Emission Factors for Grid Electricity. Ecometrica technical paper 2011. https://pdfs.semanticscholar.org/c293/469f8103b99f85c8d22794f8fbca04d86365.pdf?_ga =2.13115319.1636110668.1569601386-2055153238.1569601386 (accessed September $\left.27^{\text {th }}, 2019\right)$.

66. Lin, J.; Karhl, F.; Liu, X. A regional analysis of excess capacity in China’s power systems. Resources, Conservation and Recycling 2018, 129, 93-101.

67. Depuru, S.S.S.R.; Wang, L.; Devabhaktuni, V. Electricity theft: Overview, issues, prevention and a smart meter-based approach to control theft. Energy Policy 2011, 39, 1007-1015. 
68. IEA (International Energy Agency). Energy Technology Perspectives 2010: Scenarios and Strategies to 2050, 2010.

https://www.iea.org/publications/freepublications/publication/etp2010.pdf (accessed September $\left.27^{\text {th }}, 2019\right)$.

69. CABEE (China Association of Building Energy Efficiency). Energy Research Report of Chinese Building Sector, 2016. (in Chinese).

\section{http://www.efchina.org/Attachments/Report/report-20170710-1/report-20170710-1} (accessed September $27^{\text {th }}, 2019$ ).

70. IIASA-GAINS. Greenhouse Gas - Air Pollution Interactions and Synergies (GAINS). International Institute for Applied Systems Analysis (IIASA), Laxenburg, Austria, 2019. http://gains.iiasa.ac.at/models/gains_models3.html (accessed July 21st, 2019).

71. PBL NEAA (PBL Netherlands Environmental Assessment Agency). Trends in global $\mathrm{CO}_{2}$ emissions 2016 Report, 2016. https://edgar.jrc.ec.europa.eu/news_docs/jrc-2016trends-in-global-co2-emissions-2016-report-103425.pdf (accessed September 27 ${ }^{\text {th }}$, 2019).

72. Li, H.; Qi, Y. Comparison on China’s Carbon Emission Scenarios in 2050. Climate Change Research 2011, 7(4), 271-280. (in Chinese)

73. Schaeffer, R.; Szklo, A. S.; Pereira de Lucena, A. F.; Moreira Cesar Borba, B. S.; Pupo Nogueira, L. P.; Fleming, F. P.; Troccoli, A.; Harrison, M.; Boulahya, M. S. Energy sector vulnerability to climate change: A review. Energy 2012, 38: 1-12.

74. Valor, E.; Meneu, V.; Caselles, V. Daily Air Temperature and Electricity Load in Spain. Journal of Applied Meteorology 2001, 40: 1413-1421.

75. MUHORD (Ministry of Housing and Urban-Rural Development of the People's Republic of China). Code for design of civil buildings, 2005. https://www.sohu.com/a/218327776_188910 (accessed June 16 ${ }^{\text {th }}, 2020$ ). 
763

764

765

766

767

768

769

770

771

772

773

774

775

776

777

778

779

780

781

782

783

784

785

786

787

76. Grignon-Masse, L.; Riviere, P.; Adnot, J. Strategies for reducing the environmental impacts of room air conditioners in Europe. Energy Policy 2011, 39 (4): 2152-2164.

77. Borg, S.P.; Kelly, N.J. 2011. The effect of appliance energy efficiency improvements on domestic electric loads in European households. Energy and Buildings 2011, 43 (9): 2240-2250.

78. Rosas-Flores, J.A.; Rosas-Flores, D.; Gálvez, D.M. Saturation, energy consumption, CO2 emission and energy efficiency from urban and rural households appliances in Mexico. Energy and Buildings 2011, 43 (1): 10-18.

79. McNeil, M.A.; Karali, N.; Letschert, V. Forecasting Indonesia's electricity load through 2030 and peak demand reductions from appliance and lighting efficiency. Energy for Sustainable Development 2019, 49: 65-77.

80. Karali, N.; Shah, N.; Park, W.Y.; Khanna, N.; Ding, C.; Lin, J.; Zhou, N. Improving the energy efficiency of room air conditioners in China: Costs and benefits. Applied Energy 2020, 258: 114023.

81. Cao, J.; Ho, M. S.; Jorgenson, D.W. Co-benefits of Greenhouse Gas Mitigation Policies in China: An Integrated Top-Down and Bottom-Up Modeling Analysis. Environment for Development Discussion Paper Series 2008. (Available at:

https://media.rff.org/documents/EfD-DP-08-10.pdf accessed on 18/06/2020).

82. Burtraw, D.; Krupnick, A.; Palmer, K.; Paul, A.; Toman, M.; Bloyd, C. Ancillary

Benefits of Reduced Air Pollution in the United States from Moderate Greenhouse Gas Mitigation Policies in the Electricity Sector Journal of Environmental Economics and Management 2003, 45: 650-73.

83. McFarland, J.R.; Reilly, J.; Herzog, H.J. Representing Energy Technologies in Top-down Economic Models Using Bottom-Up Information. MIT Joint Program on the Science and Policy of Global Change 2002, Report No. 89. Cambridge, MA. 
84. Grubb, M.; Edmonds, J.; Brink, P.; Morrison, M. The Cost of Limiting Fossil-Fuel $\mathrm{CO}_{2}$ Emissions: A Survey and Analysis. Annual Review of Energy and the Environment 1993, 18, 397-478.

85. Lim, H.; Zhai, Z.J. Review on stochastic modeling methods for building stock energy prediction. Building Simulation 2017, 10, 607-624.

86. Rigby, M.; Park, S.; Saito, T.; Western, L.M.; Redington, A.L.; Fang, X.; Henne, S.; Manning, A.J.; Prinn, R.G.; Dutton, G.S.; Fraser, P.J.; Ganesan, A.L.; Hall, B.D.; Harth, C.M.; Kim, J.; Kim, K.-R.; Krummel, P.B.; Lee, T.; Li, S.; Liang, Q.; Lunt, M.F.; Montzka, S.A.; Mühle, J.; O’Doherty, S.; Park, M.-K.; Reimann, S.; Salameh, P.K.; Simmonds, P.; Tunnicliffe, R.L.; Weiss, R.F.; Yokouchi, Y.; Young, D. Increase in CFC11 emissions from eastern China based on atmospheric observations. Nature 2019, 569, $546-550$.

87. Miller, S.M.; Michalak, A.M.; Detmers, R.G.; Hasekamp, O.P.; Bruhwiler, L.M.P.; Schwietzke, S. China’s coal mine methane regulations have not curbed growing emissions. Nature Communication 2019, 10, 303. 